\title{
How is technological change affecting the nature of the corporation?
}

\section{JULIAN BIRKINSHAW}

Abstract: This paper examines how the 'digital revolution' (enabled by exponential increases in processing power and connectivity) is bringing about fundamental changes to the size and scope of firms, and to how they are organised and managed. The large, vertically integrated firms of the industrial era are being superseded by narrower, more specialised, firms that link buyers and sellers through digital 'platforms'. The traditional bureaucratic ways of organising that were invented in the industrial era are gradually being replaced with flatter and more fluid ways of organising.

The consequences of these changes are discussed, with a particular focus on public policy. Many of the current tensions between governments and big digital firms - for example, in terms of competition policy, intellectual property rules, and labour lawsare the result of a disconnect between regulations developed during the industrial era and the demands of firms operating by digital era norms. The paper identifies opportunities for institutional innovations to resolve these tensions.

Keywords: Digital revolution, industrial era, digital era, corporate strategy, organisation structure, institutional innovation, public policy.

\section{EXECUTIVE SUMMARY}

The transition to the industrial era in the late 19th century brought a fundamental shift in the scale, scope, and structure of firms. It also led to new institutions (limited liability corporations, competition laws, accounting standards) to support and monitor these firms. The history of that evolution demonstrates how the structures of corporations adapted, alongside the types of products and services, and the wider social context within which the firms operated.

An equally profound transition to a digital era is underway, causing firms and policymakers to rethink basic assumptions about what they do, and why. This paper looks at the collective effect of the digital revolution on the fundamental choices firms make about their size and scope and the implications for governments and policymakers. 
Elements of the transition are already in place. The emergence of tech giants has highlighted the superiority of platform-based business models compared to traditional linear business in markets for digital goods. However, government policies are ill equipped to deal with such corporations because regulations derive from the pre-digital era.

The author shows how changes in firm size and scope are occurring more rapidly than changes in internal organisation, which in turn are adapting more rapidly than the institutional structures surrounding firms. These lags are creating tensions between traditional and digital firms, and between digital firms and policymakers. Both management innovation and institutional innovation are needed.

Firms are shifting from hierarchical to platform models that bring users and providers of services together more efficiently. In a digital economy, the bigger firms are, the bigger they are likely to become. Large firms spend more on technological innovation, which impacts the nature of work and the number of jobs. Transaction costs between firms are falling and they need less human intervention. The greater transparency offered by technological processes makes it easier to resolve disputes and problems. On the other hand, the trend is from vertically integrated firms to horizontally specialised structures with deep expertise in one narrow area, and from standalone firms to ecosystems of interacting firms and individuals who co-evolve.

The author notes the widening gap between the growing digital economy and the shrinking industrial economy where firms employ capital and people in traditional ways. These firms often consolidate to counter the new threat. While this process of creative destruction may ultimately be good for society, the short-term costs are huge.

Institutional structures are responding even more slowly than most traditional firms. The paper examines four particular areas. Intellectual property ownership rules have adapted successfully to the economics of digital production. However, employment law, audit and measurement, and competition policy are moving more slowly. There is agreement that change is needed but not where or how. A major challenge is how to value to data and information which make digital firms so powerful.

There have been attempts at institutional innovation-for example, the General Public License for software - but instances are still rare and more research is needed to identify other successful innovations and the roles played by different actors (governments, activists, firms) in implementing them.

One theme that cuts across the entire review is the trend towards computer-based automation and how it is likely to result in wide-scale unemployment. In a competitive market, firms have to match the cost structure of their competitors, but job sharing, employing more people for fewer hours, and expanding flexible and freelance arrangements present opportunities for progress. 


\section{INTRODUCTION}

The business world is in a permanent state of flux and, among the many forces for change, technological innovation is perhaps the most important. Building on the huge advances in processing power and mobile connectivity over the last twenty years, current advances in business analytics and artificial intelligence are leading to the emergence of entirely new product categories (for example, autonomous vehicles), new ways of competing (for example, platform-based business models), and also new ways of working (for example, agile).

Most of the literature on the consequences of technological change focuses on specific phenomena, such as the transition from physical to digital products in the media sector, or the competing digital ecosystems of Google and Apple. While valuable, these studies are typically time bound in their perspective, and they are written from a particular theoretical standpoint (e.g., Evans \& Schmalensee 2016, Parker et al. 2016).

In this paper, I propose to take a step back, and to look at the collective effect of the 'digital revolution' on the fundamental choices firms make about their size and scope and how they are organised, and on the implications of those choices for governments and policymakers. If we consider a brief historical analogy, the transition to the 'industrial era' in the latter part of the 19th century brought with it a fundamental shift in the nature of firms (their scale and scope, how they were organised, etc.) and it led to the creation of a new set of institutions (limited liability corporations, competition laws, accounting standards) to support and monitor these firms. I contend that we are in the middle of an equally profound transition to a 'digital era' that is causing firms and policymakers to rethink these basic assumptions about what they are doing and why.

Many elements of this transition are already in place. For example, the emergence of tech giants, such as Amazon, Google, and Alibaba, has highlighted the superiority of platform-based business models compared to traditional linear business models in markets for digital goods. But there are also many aspects of this transition that have yet to occur. Government policies, for example, are ill equipped to regulate Facebook or Google when they exploit the personal data of their users, largely because those policies were developed in the industrial era where user detailed data did not exist.

By taking this high-level perspective on technological change, I develop a novel point of view on the challenges and opportunities facing firms and policymakers. For example, I show how changes in firm size and scope are occurring more rapidly than changes in internal organisation, which in turn are evolving more rapidly than the institutional structures surrounding firms. These lags are creating tensions between digital and traditional firms, and between digital firms and policymakers. There is a 
need for both management innovation (that is, new ways of working among traditional firms) and institutional innovation (that is, new policies and regulations) if the potential benefits of the digital revolution are to be fully realised.

The paper is structured in four parts. The first part describes the broad shift from the industrial to the digital era, and how it compares to the earlier transition from a pre-industrial (agrarian) era to an industrial one. The second part examines the implications of this shift for firm size and scope, including such things as their choices of business models and level of vertical integration. The third part looks at the implications of the digital revolution for how firms are structured and organised: for example, in terms of level of decentralisation and employment contracts with workers.

Finally, I consider the policy dimensions of these changes, and in particular I focus on the types of economic institutions that are needed to support a predominantly digital (rather than industrial) economy. It is worth noting that there are huge questions about the consequences of the digital economy for jobs in general: for example, whether there will be enough work to go round. While I touch on this issue, in terms of the responsibilities of firms in the digital economy, these broader societal concerns are beyond the scope of this paper.

\section{THE INDUSTRIAL-DIGITAL SHIFT}

While the business world is in a perpetual state of flux, many observers believe that the changes underway at the current time are highly distinctive. Brynjolfsson and McAffee (2014) talk about the Second Machine Age, which involves the automation of cognitive tasks that make humans and software-driven machines substitutes (whereas the First Machine Age, the industrial revolution, helped to make labour and machines complementary). Schwab (2017) uses the term Fourth Industrial Revolution to signify the new ways in which technology is becoming embedded within societies and the human body (the first three industrial revolutions were represented by steam engines, electrification, and microprocessors, respectively). Others have used such terms as the Information Age, the New Media Age, the Agile Age, and the Digital Age (Castells 1996, Denning 2018).

The common theme across these perspectives is that the exponential growth in the processing and transmission of information beginning in the late 1960s led to a major shift in the types of products and services sold to consumers, the internal workings of firms, and a dramatic shift in the basis of firm competitiveness.

Of course, the mechanisms by which technology has shaped firm activities and human behaviour are quite complex. For example, some studies have documented the shift from technology supporting work to technology automating work through to technology complementing human effort (Carr 2008, Davenport 1993), while others 
have emphasised the dialectic between technological innovations and social innovations that mitigate the limitations of those innovations (Barley \& Kunda 1992, Bodrožić \& Adler 2018). These nuances are important, but for the purposes of this paper I take a very high-level perspective, focussing on overall transition from the industrial era (late 1800 s to 1970 s) to the digital era (1980s to today), in order to make sense of changes in how firms compete and how they are organised. And to give some historical context to this shift I compare it to the prior transition, where the pre-industrial era gave way to the industrial era.

\section{The pre-industrial to the industrial era}

Many business historians have examined the changes that took place in Europe and North America during the period 1800-1920, as the industrial revolution took hold, first in Europe and then in the US (Chandler 1990, Horn 2007). In the middle of the 19th century, nine out of ten white male citizens in the US worked for themselves as farmers, merchants, or craftsmen, while the biggest UK firm had only 300 employees (Jacques 1996). But the technologies of automation and mass production made it possible for large firms to emerge, and around the turn of the century these firms capitalised on economies of scale and scope to dominate large parts of the economy: for example, in oil production, automobiles, chemicals, and electricity.

This shift towards large industrial firms brought with it changes in the nature of work and organisation, with the development of formalised structures and hierarchical systems of control. These new ways of working were helped along by management pioneers like Frederick Taylor and Henri Fayol (Wren 1998), who developed new techniques for enhancing quality and efficiency, though often at the expense of personal initiative and motivation.

This period of transition was also characterised by changes to the policies and regulations supporting business: what I refer to as the institutional structures of capitalism. The most important such changes were in the legal governance structures surrounding business. The Joint Stock Limited Liability Corporation came into existence in 1855 (Micklethwait \& Wooldridge 2005), and it became widely used as a mechanism to enable business people without personal wealth to attract investment and grow their businesses. During this same period, many other regulations were also put in place: for example, rules around the ownership of intellectual property and the granting of patents, the formalisation of accounting standards, rules to protect the rights and obligations of workers, and competition policies designed to prevent any individual firms from becoming too powerful.

While these economic regulations took shape, there were also changes underway in the social institutions that supported industrial firms. Jacques (1996), for example, 
shows how the concept of employees, as individuals working in a depersonalised way for large firms, emerged during this period, and how it shaped the entire discourse around management work, the nature of careers, and the system of education that supported business.

In sum, the period of transition from 1850 to 1920 resulted in fundamental changes to the business landscape, and corresponding changes in society more generally. And the consequences were also profound: there were huge benefits in terms of rapidly rising standards of living, but also costs in terms of increasing inequality, alienation of workers, and congestion and pollution.

\section{The industrial era to the digital era}

Is it possible that the current period of transition, from the industrial to the digital era, will have an equally profound impact on work and society as this earlier transition from the pre-industrial to the industrial age? My view is that it will, and it is the purpose of this paper to outline the dimensions of those changes, as suggested in Figure 1.

In today's digital economy, many of the products and services we consume are primarily digital - music, movies, books, games, news — and most physical products are digitally enabled — cars, phones, homes. Digital technology also changes the way firms relate to each other. As a result, we are seeing significant shifts in firm size and scope: for example, the emergence of 'platform'-based business models that bring users and providers of services together in more efficient ways.

A complementary shift is underway in firm structure and organisation. Digital technology makes sharing of information much easier than before, which enables firms to be less hierarchical, and more open to bottom-up decision-making. Higher levels of education among workers makes them better able to take initiative and more susceptible to intrinsic sources of motivation. These changes also make it easier for people to work remotely, and to have more flexible careers.

This paper uses the term 'digital firm' broadly, to cover a variety of firm types, including pure platform firms (Facebook and Uber), platform-enabled firms (Amazon and Apple), traditional firms selling digital products (the Financial Times, Experian), and digital service providers (Oracle, TCS) who build the infrastructure and services that enable digital firms to function. The dynamics of each type are different, but to keep the scope of the paper manageable they are considered as a single group.

Finally, there are changes underway in the institutional structures supporting business. These include new models of governance for firms, new rules around 


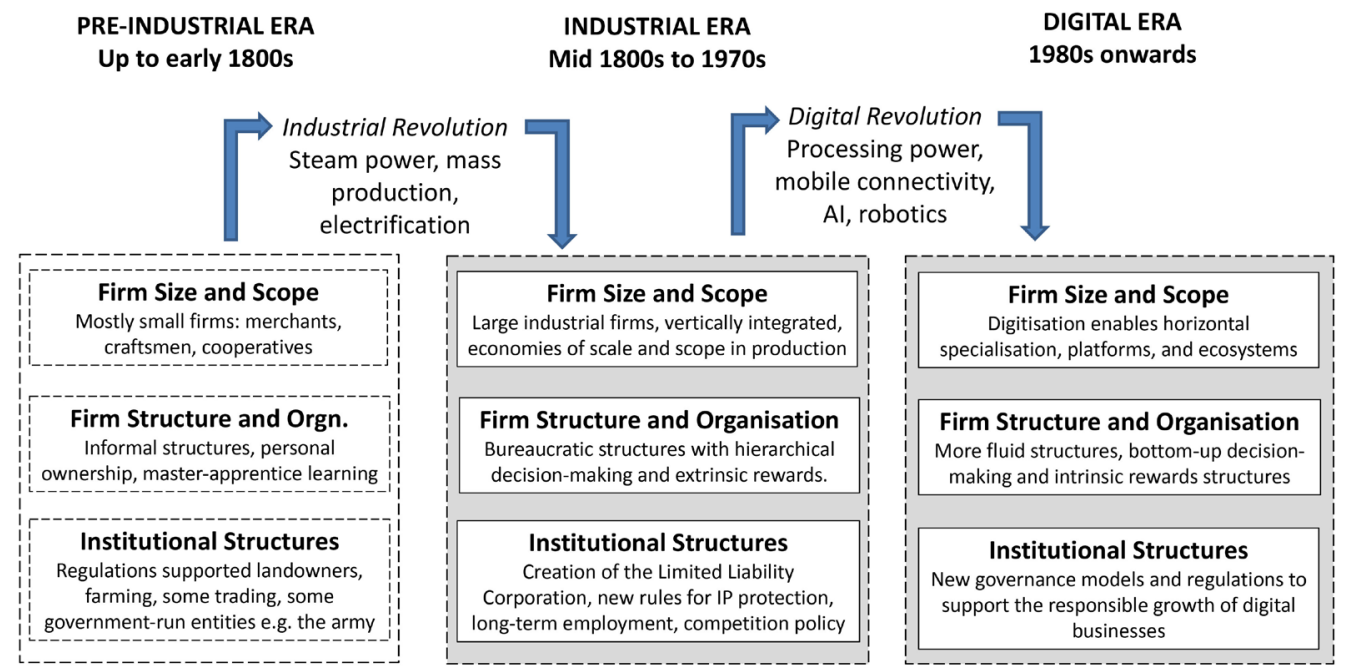

Figure 1. Changes from the industrial to the digital era.

intellectual property, changes to accounting regulations, employment law and competition law, and so forth.

These three dimensions are of course linked together, but they are only loosely coupled. In my view, the digital revolution has spurred relatively rapid changes in firm scale and scope, as exemplified by the likes of Amazon, Facebook, Uber, and Airbnb. There have been some innovations in firm structure and organisation (Birkinshaw 2010), though most large firms are still struggling to embrace the new digitally enabled ways of working. And progress is even slower in the institutional structures that support business. Indeed, to a significant degree, these economic and social institutions surrounding business are stuck halfway between the industrial and digital eras.

In the remainder of this paper, I will examine each of the three dimensions (firm size and scope, firm structure and organisation, institutional structures) in greater detail, looking closely at the ways they are being affected by the digital revolution, the consequences of these changes, and the challenges that remain for businesspeople and policymakers.

\section{FIRM SIZE AND SCOPE}

The shift from the industrial to digital era has already had a profound effect on the size and scope of firms. These changes are the result of some fundamental differences between the economics of production of physical and digital products (or 'atoms versus bits' (Negroponte 1995)). 
- Digital products are distinctive in a number of important ways (Shapiro \& Varian 1998). They are susceptible to network effects, whereby the value experienced by one user increases as the number of other users increases. They often have greater switching costs for users. They are 'non-rivalrous', meaning that many people can use the same product or service at the same time. They are often 'co-created' by the people using them. Taken in aggregate, these features of digital products can result in firms generating increasing returns to scale (Arthur 1994). This is an important point of difference with physical products: the traditional logic of industrial production assumed that firms generate economies of scale up to a certain level, after which the costs of complexity resulted in diminishing returns to scale, thereby putting a limit on the size of firms. However, digital firms (think of Google or Facebook) face no such limits in their core areas of business, so the bigger they are, the bigger they are likely to become.

- Digital technology is enabling increases in the operational effectiveness of firms. Since the 1970s, firms have been investing large sums of money on information technology, and their expenditures continue with every new generation of technology. A large bank with 100,000 employees will typically employ 20,000 or so people in IT activities. Recent technological advances, especially in the area of artificial intelligence, are now becoming increasingly influential. Whereas earlier IT investments typically led to the automation of manual or repetitive tasks, AI-based systems are increasingly used in professional tasks, from auditing to legal work to medical diagnosis (Davenport \& Ronanki 2018). While the evidence for productivity and competitive benefits from these types of investments is still unclear, there is a broad consensus that digital technology is gradually replacing large numbers of jobs that were traditionally being done by humans.

- One of the consequences of information technology being used within and between firms is that transaction costs are falling (Williamson 1975). Firms frequently transact with one another without any human intervention, and greater transparency is, of course, making it easier for disputes and problems to be resolved. Taking this trend even further, some of the leading-edge blockchain firms are experimenting with so-called smart contracts (Christidis \& Devetsikiotis 2016), which are designed to specify and execute transactions with no human involvement. This trend, of course, means that the benefits of firms as entities that internalise transactions, are falling considerably, making market-based transacting more efficient. 
So what is the effect of these trends on the size and scope of the firm? The story that emerges here is quite complex, because some of these trends actually have countervailing effects (for example, digital firms are smaller in some respects than their industrial counterparts, but bigger in other ways). Taking a high-level view, some important shifts can be identified.

\section{From vertically integrated to horizontally specialised}

One of the most profound shifts from the traditional industrial era to today's digital era is around the vertical versus horizontal scope of the firm. Vertical scope refers to the number of linked segments in a single value-chain that a firm participates in; horizontal scope refers to the number of (customer-facing) markets a firm competes in. These choices are not mutually exclusive - firms can be narrow or broad on each dimension.

Looking back to the post-war years, many firms operated in a vertically integrated way: Ford Motor Co. had its own rubber plantations for its tyres, IBM developed its own processors, and so on. Gradually, it became clear that this level of vertical integration was inefficient and lacked flexibility, so Ford, IBM, and others sold off their component manufacturers and their distribution channels, and focussed on a narrower set of activities where their 'core competences' were (Prahalad \& Hamel 1990, Quinn 1992,). A few industries, notably oil and gas, retained their vertically integrated structure because of concerns about the volatility of input prices.

Moving into the 1990s and 2000s, this trend towards greater horizontal specialisation continued, and the norm among digital era firms is to aim for narrow expertise in one business area, but on a global scale. Google and Facebook exemplify this trend, as do 'unicorn' firms like Uber, WeWork, and Palantir. There are a few noteworthy exceptions, such as Amazon and Tencent, but these are firms with broad horizontal scope (that is, selling a range of products or services to similar customers) rather than vertical scope, and they achieve their scope by leveraging a particular set of competencies around gathering and using customer information.

\section{From product to platform}

One of the most visible changes over the last decade is the emergence of 'platform' businesses. A platform is simply a technological interface that mediates transactions between two or more sides. Fast-growing firms such as Uber, LinkedIn, WeWork, and Facebook are pure platform businesses. Others, including Microsoft, Apple, and Amazon, are platform-based businesses operating with a mix of physical and digital offerings. 
Platform businesses are different to product businesses in a couple of key ways. First, they offer increasing returns to scale, and indeed they are often 'winner-takes-all' businesses. Google's paid search business, for example, gets better the more people use it. Second, they often operate in a very low-cost way, with few assets. As many have observed, Uber is the world's largest taxi service in the world, but it owns no vehicles, while Airbnb is the biggest room-booking service in the world but owns no properties. If one looks at the ratio revenues per employee, Uber, Apple, and Google are over \$1million, compared to traditional employers such as Starbucks or McDonald's at $\$ 84,000$ and $\$ 66,000$, respectively — approximately twenty times higher.

Of course, a platform business is a particular form of horizontal specialisation, whereby the firm does one very narrowly defined activity so well that large numbers of others choose to use its services. What makes a platform distinctive is the ability to capture and utilise information about its network of customers and suppliers. This is what makes the likes of Google and Facebook so powerful, and it is of course contributing to the current backlash against them.

\section{From stand-alone to ecosystem}

A third feature of the digital economy is the increasingly important role of business ecosystems in shaping consumer and firm behaviour. An ecosystem is a community of interacting firms and individuals who co-evolve and tend to align themselves with the direction set by one or more central companies (McIntyre \& Srinivasan 2017). To some extent, firms have always built long-term relationships with suppliers, partners, and customers: consider, for example, the network of component suppliers to large automobile manufacturers like Volkswagen or Ford. But the network effects and switching costs associated with digital economy products make ecosystems significantly more important than they used to be. A well-known example is the mobile phone industry, where Nokia and its Symbian operating system lost out to Apple's iOS and Google's Android in large part because it was not able to persuade sufficient developers to build applications on its platform. Former Nokia CEO Stephen Elop observed in 2010 that 'The battle of devices has now become a war of ecosystems.'

\section{IMPLICATIONS AND CONSEQUENCES}

In sum, the digital revolution has enabled the emergence of a breed of horizontally specialised, platform-based players sitting in dominant positions at the centre of their ecosystem of suppliers, customers, and complementors. Seven of these are among the 
top-ten most valuable listed firms in the world: Apple, Amazon, Alphabet, Facebook, Microsoft, Tencent, and Alibaba (the other three are Berkshire Hathaway, JPMorgan, and Johnson \& Johnson). While there were dominant firms during the industrial era-for example, in oil (Shell, Exxon), chemicals (DuPont, Bayer, ICI), automobiles (Volkswagen, General Motors, Toyota) - there is a current sentiment in the business discourse that these large digital firms are becoming overly powerful, in large part because they are operating according to a different economic logic to their industrial era predecessors. Let us consider some of the implications of this trend.

\section{Dichotomy between industrial and digital sectors}

While digital firms are operating according to these new economics, there are many firms still operating according to the traditional logic of the physical world: for example, making and selling industrial and consumer products. These traditional parts of the economy typically pay lower wages, even though they employ larger numbers of people, and they attract less capital investment. A gap is therefore opening up between these two sectors of the economy - the industrial firms who employ capital and people in traditional ways, and digital firms who exploit their control over flows of information and capital between other market participants.

This trend, in turn, has several predictable consequences. Traditional firms are under pressure from investors and analysts to become more digital. This means higher levels of investment in technology to automate and simplify activities, and outsourcing of low-value-added activities to third parties or to lower cost countries. It also leads to consolidation, with former competitors merging as a means of maintaining market power in the face of new threats. All of which tend to result in fewer jobs.

Traditional firms are also going out of business more often than they used to. Studies have shown that a firm's 'lifespan' on the S\&P 500 has dropped from thirtyfive years to about fifteen years over the last thirty years (Innosight 2018). And the number of high-profile bankruptcies, especially in the retail and technology sectors, is on the rise. The consequences here are significant, because while this process of creative destruction (Schumpeter 1934) is ultimately good for society, the short-term costs when large firms downsize or even go out of business are huge.

\section{Consumer and government backlash against digital firm dominance}

The nature of capitalism is that small numbers of firms typically end up in dominant positions, but with various political and social mechanisms in place to keep these firms in check. For example, big industrial firms over the years, from Standard Oil 
and General Motors to IBM and AT\&T, became dominant for a while and then subsequently lost their position, sometimes through an enforced break-up, sometimes through the emergence of new competitors and the problems of excessive size and complexity.

Will the same happen today? There is a case for allowing the likes of Google and Facebook to continue, relatively unchecked, and to allow the process of creative destruction to take its natural course. But there is a growing sentiment in the business press that they are becoming too powerful, and that governments need to take a more activist role in regulating their activities (e.g., Lynch 2017). But there is little agreement about how best to do this, as we discuss in more detail below.

\section{Rethinking what firms really do}

At a more abstract level, it is interesting to consider what the impact of the digital revolution is on the overall nature of the firm. As discussed earlier, one of the fundamental points about digitisation is that it reduces transaction costs, thereby making it easier to coordinate many types of transactions through market-based mechanisms (Coase 1937, Williamson 1975). Artificial intelligence - for example, voice recognition software - is accelerating this trend further. For example, when you say to Alexa 'order more dog food,' a chain of activities is initiated that leads to the delivery of a fresh supply of food twenty-four hours later, with little or no human intervention. This work is coordinated by a single firm, Amazon, but it often involves third parties (makers of dog food, delivery companies) whose systems interact seamlessly with Amazon's.

Looking to the future, then, it is interesting to speculate on 'what's left for firms' when the traditional work of firms is either done through market transactions, or by robots and computers that do not require human intervention. While economic theory might argue that firms are little more than a nexus of contracts (Jensen \& Meckling 1976), a sociological perspective suggests that firms are distinctive in a number of respects. They are mechanisms for coordination, and especially for sophisticated forms of coordination that involve multiple inputs and trade-offs over time. Firms also have an identity or purpose that engenders higher levels of discretionary effort on the part of those working for them (Kogut \& Zander 1996, Moran \& Ghoshal 1999). One of the challenges for firms, then, is how to reinforce these distinctive attributes, while continuing to stay competitive in an increasingly automated and digitised world. 


\section{FIRM STRUCTURE AND ORGANISATION}

The shift from the industrial to the digital age has enabled significant changes in how work gets done. Again, some of these changes have been underway for a while. Studies in the 1980s were already predicting the demise of the middle manager because the computer revolution was enabling the sharing of information down and across organisations more efficiently than before (e.g., Leavitt \& Whisler 2000). And leading thinkers such as Handy (1989) were predicting the rise of freelance workers who sold their services back to firms, and a corresponding reduction in the numbers of traditional employees.

The digital revolution is affecting the internal structure and organisation of firms through several linked mechanisms.

- Digital technology affords far more efficient collection and sharing of information. It is possible to monitor and analyse every conversation in a contact centre, every action by an assembly line worker, and every stage in a logistics chain, all in real time. Information about customer behaviour, productivity levels, and business performance can likewise be shared at almost no cost.

- Digital technology enables real-time collaboration when people are not co-located. Many software products are designed to allow multiple people to work on them simultaneously. Video conferencing is now as cheap and simple as calling. Surgeons can perform some procedures remotely, by using videogame-like controls while the medical team is in another location. In the online learning world, some business schools have created 'wow rooms' where up to 100 students appear live on video, conducting case-study discussions as if they were in the same location.

- Digital technology has enabled the modularisation of work, meaning that by conducting work in discrete units with interfaces between those units specified in advance, a system becomes more loosely coupled and therefore more easily adapted to shifting circumstances. While these concepts of modularisation were developed in the IT world, they are increasingly being applied in other non-technological settings as well (Baldwin \& Clark 2000, Yoo et al. 2010).

- Finally, digital technologies are not just enabling changes in how we workthey are also providing inspiration for new management techniques. The shift from mainframe computers to PCs gave impetus to the empowerment trend of the 1980s. More recently, 'agile' emerged as a software methodology, made possible by new programming languages, and it has now inspired new management techniques based around decentralised teams, iterative development, and close attention to the user experience. 
These new digital methods are leading to significant changes in how firms are working. To be clear, the process of change here is evolutionary rather than revolutionary, and many of the trends described below are still work-in-progress. But when you put them together, it is possible to make out a very different set of structural and organising principles to those used by traditional industrial-age firms. We consider first how firms are organised internally, and then how employee-firm working relationships (in terms of space and place) are evolving.

\section{Internal firm structure and organisation}

It is possible to separate out the activities of firms into a number of linked areas: how work is coordinated, how decisions are made, how objectives are set, and how employees are motivated (Birkinshaw 2010). For each of these, we can identify a traditional set of principles that were developed in the early part of the 20th century and fit with the classic industrial-era logic, and we can map out an alternative set of principles that are increasingly relevant in today's digital world.

\section{Coordinating activities}

The standard industrial-era model of coordination was bureaucracy, the use of standardised rules and procedures to ensure conformity of behaviour and to generate consistent outputs. But thanks to digital technology, the need for formal rules to ensure conformity is much lower: the availability of information at the fingertips of employees means they are more likely to be able to align directly with others, without senior management or rule-based interventions.

In today's digital-era firms, coordination is therefore more likely to be achieved through emergent means, with employees making their own judgements based on real-time responses to the demands of the marketplace. Rather than bureaucracy, today's firms are more likely to be a meritocracy, where knowledge and judgement are privileged over formal rules, or an adhocracy, where action is privileged (Birkinshaw \& Ridderstråle 2017).

\section{Making decisions}

A key feature of the standard bureaucratic model of work is hierarchy: that is, the legitimate authority of one individual over others. In industrial-era firms, it was assumed that important decisions would be made by those at the top of the hierarchy, with those lower charged with implementing those decisions. However, for the reasons already discussed, technological change has put more information into the hands of front-line employees, and they are for the most part better educated and better able to make good decisions themselves. There is also a greater competitive intensity in many 
sectors today, which puts a premium on those firms that are able to respond quickly as opportunities emerge. As a result, we are increasingly seeing digital-era firms making decisions through collective wisdom, meaning that the aggregated insights and expertise of a large number of people are brought together to plot and implement a course of action.

\section{Defining and pursuing objectives}

Consistent with the more top-down way of working in industrial-era firms, the key principle here can be referred to as linear alignment, which means defining an intended outcome, say five years into the future, and then defining the specific plans and targets for all the various parts of the firm over the coming years, to ensure that the outcome is achieved.

While this principle of linear alignment is still very relevant in the world of business today, digital-era firms are experimenting with alternative principles as well. One problem with linear alignment is that the state of flux in the marketplace makes it very hard to commit to explicit long-term targets. Another problem is that such targets leave little scope for individuals to make their own choices. So many digital firms are using more fluid objective-setting procedures, and relying on broad expressions of purpose to generate coherent activity from their employees. The term sometimes used for this alternative principle is obliquity, which is the notion that goals are often best achieved when pursued indirectly (Kay 2011).

\section{Motivating employees}

Industrial-era firms were built on 'Theory X' assumptions (McGregor 1966) that motivation is extrinsic: that is, that people work hard to generate material rewards. As we move into the digital era, extrinsic rewards are still relevant and especially so for people who are working at lower levels in firms. But, as observed earlier, digital technologies provide greater opportunities for people to make their own choices about how they spend their time in the workplace and at home, and of course they have also made workers (especially in advanced economies) wealthier. Most digital-era firms therefore focus more on intrinsic ('Theory $\mathrm{Y}^{\prime}$ ) approaches to motivation, including providing autonomy for workers, helping them develop personal mastery, and providing them with purpose and meaning in their working lives (Pink 2011).

These alternative principles of structure and organisation are rarely applied in a consistent way, but they are manifesting themselves in a lot of different places. For example, many of the 'born-digital' firms discussed earlier, such as Google, Facebook, and Amazon, have developed management practices built on these principles. And many of the currently popular management ideas around today, such as agile, Holacracy, design thinking, and lean start-up are also consistent with these new principles. 


\section{Employment relationships between individuals and firms}

For individual workers, the digital revolution has enabled a general upskilling in the workplace, with more individuals having both the means and the motive to rethink their relationship with their employers, and to consider the possibility of working for themselves. There is also a generational shift underway, with many studies pointing to aspects of the so-called Generation Y employees (and now Generation Z) that make them more open-minded to switching between jobs and careers than previous generations (Martin \& Tulgan 2001).

A separate trend, which is even more closely linked to the digital revolution, is the emergence of greater opportunities for people to work freelance than ever before. Technology has essentially 'democratised' the world of entrepreneurship. To be a freelance worker today, you need an internet connection and a service to sell, whether it is coding, copywriting, or cartoon drawing. To be a taxi driver you need a car and a GPS. And if you need access to money, crowd-funding platforms and micro-finance schemes make this easier than ever before.

A third aspect of the digital revolution that affects individual-firm employment relationships is the ease of working remotely. Of course, this trend has been underway for decades, thanks to first the Internet and then the mobile revolutions. What has changed over the last decade or so is the level of acceptance in large firms towards different work arrangements. Large employers such as Deloitte and IBM encourage their white-collar employees not to come to the office every day. Office space providers such as WeWork are creating attractive alternative locations, alongside the coffee bars and home offices people have been increasingly using.

In sum, the trends supporting freelance working that have been underway for forty years or so, are now coming together, and resulting in material changes in relationship between workers and employers. A recent study by the RSA estimated there are 1.1 million 'gig' workers in the UK, defined as people who are paid per individual job without a salary or retainer (Balaram et al. 2017). And interestingly, these gig workers are spread across the spectrum of workers, with 59 per cent of these people being professional or white-collar workers, 33 per cent in trades such as plumbers, and only 19 per cent in low-end delivery or taxi-driving types of work. While it is true that many of the latter category, working for the likes of Uber and Deliveroo, are doing this work because no alternative exists, the majority of professional and trade workers are happy eschewing a salaried job. For example, a recent study the author was involved with found that 59 per cent of independent consultants saw their freelance status as a deliberate choice, 92 per cent were moderately or very satisfied with their lot, and 50 per cent were making more money than when they worked for a large firm (Hill 2016). 


\section{Consequences and implications}

While there is a general recognition that digital ways of working are faster and more effective than traditional bureaucratic ones, large traditional firms are struggling to adopt them in a meaningful way, for the simple reason that internal structures and processes tend to be self-reinforcing. In contrast, many fast-growing digital firms are 'born agile', which means they adopted these non-hierarchical and self-organising structures from the outset. To be sure, there are efforts underway in large firms to introduce these new models: agile working methods, for example, are now being adopted in many places (Denning 2018). But one should not underestimate the challenges in trying to change the accepted way of structuring a firm that has been around since the early parts of the industrial era.

One alternative to changing their internal structures is for established firms to build ecosystems where they collaborate with start-ups and faster moving digital-age firms. This enables each type of firm to play to its strengths, but it puts a premium on the quality of interaction between firms. Again, most established firms do not do this naturally - they are still rooted in a much more closed-minded and protective world-view from their industrial-age origins.

As for the relationships between firms and workers, the trend is clearly towards flexibility and choice, and again there are good reasons to encourage greater movement. Of course, there is a need for people doing poorly paid work to have legal protections in place, but it would be wrong to generalise the needs of that set of workers to those of better paid and professional workers. In this area, the direction of development appears to be clear, but the regulations and social norms surrounding the employment contract still need to adapt further.

\section{GOVERNMENT POLICY AND REGULATIONS}

The final part of this paper considers how the institutional structures surrounding business are evolving to support the shift from the industrial to the digital era. As noted at the outset, our point of view here is that these types of institutions almost always change in response to (rather than in advance of) changing business practice, frequently with a lag of many years. For example, new banking regulations were put in place following the global financial crisis of 2007-8, but not for about five years, while the debate about whether Uber and Deliveroo drivers are employees, freelancers, or something in-between has stimulated a review of labour laws, but without any definitive changes yet. 
It is useful to frame this discussion somewhat more broadly than just in terms of government policy, because there are a range of institutions that regulate the activities of business, and not all of them are written into formal rules. We can identify both economic institutions of capitalism (e.g., Soskice \& Hall 2001, Williamson 1985), including such things as legal forms of corporations, competition policy, intellectual property (IP) rules, and employment law, and also social institutions of capitalism (Granovetter 1992, Hollingsworth \& Boyer 1997), which are the norms that develop in society around how firms and individuals working in them should behave. For example, in the recent case of Facebook making data available to Cambridge Analytica, the wrongdoing in narrow legal terms was small, but the moral outrage (a sense that Facebook had transgressed social norms) was huge.

To anticipate one of the key conclusions: the slow pace of innovation in these institutional structures is potentially problematic, because the capitalist system is only as good as the institutions that shape it. Many of the current problems in the business world (for example: excessively powerful digital firms; short-term behaviour in stock market listed firms; lack of clarity over data privacy; and lack of protection for lowend freelance workers) are enabled by institutions that are not fit-for-purpose. If we want to enhance the contribution of firms to society, we need to give careful attention to institutions that surround them, and to develop a perspective on how they can become more effective.

To structure the remainder of this section, I will look at four different institutional structures in turn. In each case, I will consider how those institutions are in the process of transitioning from their origins in the industrial era to their current form in the digital era. Note that this is by no means a comprehensive set of institutional structures. These four were chosen because they are directly linked to the activities of firms, but other institutions, for example education, access to finance, and the legal governance of firms, are also important and should be given due consideration in the future.

\section{Ownership of intellectual property}

One of the central pillars of an effective capitalist system is a robust set of rules around property rights. Clear property rights give investors the confidence to make investments, and they enable people and firms to divide up the returns from such investments in a fair way.

In the context of this paper, the important property rights we need to consider are those around intellectual property, which includes such things as 'original forms of expression' that are protected through copyright law, inventions and discoveries protected through patents, and particular words or symbols protected through trademark law. 
As a broad generalisation, the norm among industrial era firms was always to protect their intellectual property. Such properties (for example, trademarks and patents) were often a valuable source of economic rent. Several influential theories of the firm, such as the resource-based and knowledge-based views, built on the logic of the firm as a bundle of distinctive assets (e.g., Grant 1996).

The digital revolution has led to some significant changes in how firms and individuals think about intellectual property right protection. This shift in perspective is most advanced in the world of software development, and the emergence of the 'open source' movement (e.g., Hippel \& von Krogh 2003). As we discussed earlier, the existence of network effects in how computer systems function creates the opportunity for firms to become de facto monopolies. And of course, such monopolies did start to emerge in the 1990s, with Microsoft Windows/Office as the best-known example, but with many other firms (Intel, Cisco, IBM) also having dominant positions in their chosen product areas.

Concerns about the dominance of Microsoft (and to a lesser degree other firms) led to pressure for additional regulation, and a spate of cases against Microsoft on the grounds that it had abused its dominant position in one market in order to control other markets. But perhaps of greater long-term importance, the open source software movement took shape during this time (1990s). This movement had many actors, each pursuing slightly different objectives, but the common underlying belief was that growth, innovation, and economic welfare more generally would benefit from the creation of technological systems that were not owned by an individual or firm. For example, Tim Berners Lee is credited with inventing the World Wide Web, and in 1993 he persuaded the directors of CERN (where he worked) to release the source code of the Web into the public domain, making it freely available to anyone, without licensing fees.

However, making software free is not as simple as it sounds: there is little incentive for people to invest in products they will not generate income from, and there is a risk of appropriation of this software by for-profit firms. In part to overcome these problems, the open source software movement, led by Richard Stallman, came up with a clever solution - the notion of a General Public License (Williams 2002). This was a software licence which 'guarantees end users the freedom to run, study, share and modify the software' (Wikipedia). It was also defined in such a way that derivative work could only be distributed under the same licence terms, thereby preventing forprofit firms from appropriating the commonly created product for their own private benefits.

While there is scope for further progressive changes in this area, the General Public License for software provides a good example of how a change in rules reflected the changing economics and demands of the digital era. 


\section{Measurement and audit of firm activities}

A second institutional structure is the accounting standards used to measure, monitor, and value the activities of firms. These standards are central to a well-functioning capitalist system, because they enable investment, they facilitate a market for corporate control, and they allow corporate taxes to be collected in a fair way.

The existence of accounting standards to support business activity can be traced back to the invention of double-entry bookkeeping in 1494. Today's accounting standards are essentially a product of the industrial era: the United States' Generally Accepted Accounting Principles, for example, were established in 1939. But these principles are continuously being reviewed and updated, to reflect the needs and realities of current business practice.

The big challenge in accounting standards, in the context of this paper, is how to value intangible assets. These are defined as non-monetary assets without physical substance, and they include intellectual property, as discussed above, but also even more hard-to-define things such as reputation, long-term relationships, organisational practices, and human capital.

During the industrial era, intangible assets were already an important part of the value of a firm, but the importance of physical plant and equipment, buildings, land, and other tangibles was also substantial. However the emergence of the digital economy has led to a situation where tangible assets represent an increasingly trivial percentage of the real market value of a firm. For example, Spotify's tangible assets (plant and equipment) represented less than 1 per cent of its market valuation in 2018 (Bryant 2018). Looking more broadly, in 1975, 17 per cent of the market value of the S\&P 500 was based on their intangibles, whereas in 2015, 84 per cent of their value was intangibles. This is a dramatic change, and arguably it is an understatement, because the S\&P 500 includes many traditional industrial firms as well as digital firms. It seems we are moving to a world of 'capitalism without capital' (Haskel \& Westlake 2017).

It is easy to understand why intangible assets are more important to firm success in the digital era than in the industrial era. As we observed earlier, the born-digital firms such as Facebook, Uber, and Spotify operate technology platforms where their entire value lies in the relationships they create and the information they hold.

But this raises an interesting question: how are accounting standards evolving to reflect this shift towards intangible value? The current evidence suggests they are not, at least not in any substantial way. Of course, there are mechanisms for putting intangible assets on a firm's balance sheet. When an acquisition is made, the difference between book and market value is defined as 'goodwill', and this sum has to be reassessed every year and if it has gone down an impairment is made. There are also 
mechanisms for putting specific intangibles onto a balance sheet: International Account Standard 38 sets out the criteria for recognising and measuring them. However, these are fundamentally conservative measures, and in practice most intangibles do not get formally valued. It is so hard to derive a reliable and valid number that the default is to give such assets no value rather than the wrong one.

Attempts have been made over the years to take intangible asset valuation more seriously. In the late 1990s, for example, the Intellectual Capital movement sought to create formally recognised measures of firm Intellectual Capital (Edvinsson \& Malone 1997, Lev 2000). But these efforts never took hold, essentially because measurement was so difficult.

Another recent effort is the Sustainability Accounting Standards Board (SASB), founded in 2011, which is an independent organisation 'dedicated to enhancing the efficiency of the capital markets by fostering high-quality disclosure of material sustainability information that meets investor needs.' SASB is backed by many highprofile firms, and it is seeking to get its standards incorporated into the $10-\mathrm{K}$ forms that all US public companies have to fill out. However, it is currently operating in an informal capacity.

In sum, formal changes to the institutions of measurement and audit are happening very slowly. Industrial-era accounting principles are still being used to account for the activities of digital-era firms operating by a rather different set of rules. It is perhaps unsurprising, then, that so many digital firms are opting to use private capital markets, where the limitations of these accounting methods are less of a hindrance.

\section{Competition policy}

While firm strategy is all about achieving above-normal profits, there are clearly limits to the benefits, from a societal point of view, of allowing this to happen. So an important institution in any well-functioning capitalist system is competition policy: that is, a set of rules and safeguards to protect the interests of consumers. Firms have historically used a variety of tactics to earn excessive levels of profit, including the formation of trusts and cartels, full-line forcing, predatory pricing (to drive out competitors), and tacit forms of collusion.

The origins of competition policy in the United States dates back to the late 1890s, with the emergence of giant 'trusts' controlling large segments of the economy, and the passing of antitrust legislation, starting with the Sherman Act in 1890 and the Clayton Act in 1914. The UK and Europe did not have formal competition rules in this period (for example, IG Farben in Germany was created in the 1920s in the manner of the US trusts), but following World War II, policies were developed along the lines of those in the US. 
During the post-war years, competition policy was used quite extensively as a means of keeping big business in check, both through the blocking of proposed acquisitions, and occasionally through enforced break-ups of overly dominant firms such as AT\&T. As explained by Khan (2016), competition policy in the 1970s and 1980s became strongly influenced by the Chicago School approach to antitrust, which in essence meant that excessive consumer prices were evidence of market dominance. This set of policies was, of course, built around a linear industrial world-view, whereby the price paid at each step of the business system was a function of the relative bargaining power of the trading parties. But today's digital economy operates by a very different set of competitive rule, where this long-established approach to tackling companies with hugely dominant market positions looks increasingly redundant.

The problem, of course, is that platform-based businesses do not price their products in a traditional linear way. Taking ride-sharing as an example, Uber is seeking to be the dominant player in its market by deliberately charging less to passengers, so that additional drivers make themselves available, thereby increasing the speed of service and therefore the net benefits to drivers and passengers. Because of the network efforts at play, market dominance does not always manifest itself in terms of higher prices to consumers (Rochet \& Tirole 2003).

To put this point in simple terms, competition authorities used to focus on excessive consumer prices as evidence of dominant behaviour. But today, the big-tech firms sustain their dominance by providing their services to consumers at very low cost. In traditional industry parlance, these firms are more like monopsonists (that is, one buyer of services) than monopolists (that is, one seller).

To what extent is this new form of dominance a problem for consumer welfare? We as consumers are benefitting from getting valuable services search as Internet search for free, even though we are handing over information about ourselves to Google in return. But there are potentially costs at a societal level. The biggest is that the barriers to entry for new firms in these winner-takes-all markets are enormous, which means that the likes of Facebook, Google, and Tencent can gradually raise prices on both sides (for advertisers and for consumers), secure in the knowledge that other firms cannot take them on. There is also the less persuasive, though not irrelevant, argument that these dominant players are hurting important parts of societythe collapse of traditional high street retailing at the expense of Amazon being the best-known example. Finally, there is always a risk that dominant firms will use their power to kill off innovative competitors. Amazon has bought more than sixty firms in the last decade, while Facebook has bought Instagram and WhatsApp, and has sought to buy Snap, its latest competitor.

In sum, there is a growing disconnect between the business models used by digital firms and the competition policies being used to police them. This problem has been 
recognised in the popular business press and in academic writing (Khan 2016), but progress in resolving it has been slow.

There are some signs of progress: for example, in 2016, the European Commission fined Google $€ 2.4$ billion for manipulating its search engine to boost its own comparison-shopping business, and in 2018 there was a further fine of $€ 4.3$ billion for illegal practices relating to its Android operating system. Facebook has also been fined, but much smaller amounts - a penalty off $\$ 112$ million for reneging on a promise not to integrate WhatsApp data with that of its main app, and a fine of $£ 500,000$ for its part in the recent Cambridge Analytica case. These tiny sums (for a company of Facebook's size) may be indicative of the underlying problem: namely, that the penalties were defined under a different set of assumptions about what constituted anti-competitive behaviour.

\section{Employment law}

The fourth set of institutions we consider here are the laws and regulations around employment.

Employment law over the centuries has been shaped by a range of economic, political, social, and technological factors. As the first country to industrialise, the UK was at the forefront in developing laws to protect individuals working in factories: labour unions were decriminalised in 1867, and National Insurance payments were started in 1911. The model of work that emerged from this process of industrialisation created the notion of an 'employee' as we know it today-someone who is given work to do, based on the needs of the firm and through the legitimate authority of the boss, in return for which they get an acceptable wage plus various protections and rights afforded to them through the national legal system. Of course, this model varies significantly from country to country: for example, workers have fewer rights in the US and more in France. But the key idea here is that individuals have traditionally faced a binary choice: they can work for themselves, and bear all the risks and costs associated with finding ad hoc work, or they can take the security and comfort of working for a firm, and doing what they are told.

As we have discussed already, the shift to a digital economy is making this traditional distinction between the two types of work unsustainable. Once again, it is the platform-based business model that is creating the tension between existing laws and regulations and emerging practice. To use the modern vernacular, most of the work done on platforms is 'gigs'-for example, a consulting project for a client, cleaning a home, renting out a room for a night, or performing a menial task on a computer. These pieces of work are discrete, and in theory the worker chooses whether to do each piece of work. But, in practice, the platform firm is often the only source 
of employment for the individual. In some cases, gig workers are essentially losing all the rights they used to have as employees, but without any of the security of fixed employment.

What is the right way forward for employment law in the digital era? One welldiscussed idea is that individuals should have the opportunity to select their worker status from a number of options, including full employment, freelance work, and some sort of 'third status' hybrid that gives some of the benefits of employment but not all, in return for higher levels of freedom. In the US, for example, Seth Harris and Alan Krueger have argued for the introduction of an intermediate category, the 'independent worker' who would get some protection, around collective bargaining rights and social security, but without recourse to basic standards such as wage and hours protection (Prassl 2017). In the UK, a version of this third worker category already exists, and there is some discussion about whether additional categories should be created, to provide individuals with greater freedom to select the model that suits their needs (Balaram et al. 2017).

While changes such as these are now taking shape, they may not be sufficiently well thought out to address the root cause of the problem, which is that employment in the digital era is fundamentally different from what it was in the industrial era. Further changes in these institutional structures are likely to be required in the years ahead.

\section{Other institutions}

The four institutional structures discussed here are perhaps the most important in understanding the shift from an industrial to a digital era, but there are other supporting institutions as well, including laws of incorporation, the educational system, and professional qualifications. One particularly worth noting, because of recent developments, is the nature of media organisations in a digital world. Because of concerns about 'fake news', platform firms such as Facebook are under pressure to take responsibility for the information they share: that is, to recognise that they are publishers. A recent UK white paper, for example, recommended a new category of tech company that was somewhere between a 'platform' and a 'publisher' (DCMS 2018). Again, this case underlines the challenges regulators face in adapting to new business practices.

\section{CONCLUSIONS}

By taking a broad and historically grounded perspective, this paper has sought to shed light on how the digital revolution is changing the nature of the firm - and how the firm is regulated by society. In this concluding section, I will consider briefly the 
boundary conditions around this argument, then I will summarise some of the main points emerging from the analysis.

In terms of boundary conditions and limitations, the paper focusses primarily on the tech sector: that is, the big-tech companies like Google, Facebook, and Amazon, and also the more traditional firms in media, banking, and consumer goods that are competing with them. But clearly there are many traditional players in extraction, manufacturing, and distribution, as well as the entire government sector, where the forces for change brought about by digital technology are much weaker. In these more traditional sectors, new business models and new ways of working are emerging at a much slower pace. The paper also focusses on the US and UK economies, which are liberal market economies (Soskice \& Hall 2001) in which new business models and new ways of working are broadly encouraged. Other developed economies with less liberal norms (for example, Germany, France, and Japan), as well as growth economies such as China and India, are likely to see somewhat different patterns of adaptation. We can expect the broad proposition - that institutional change lags the changes made by firms - to be true across these countries, but the specific ways they are adapting are hard to predict. It would be interesting to document these cross-country differences in future research.

In terms of key points, first, there are some dramatic changes underway in the nature of firms, and more specifically in the emergence of a small number of highly powerful digital firms that operate according to a different economic logic to traditional industrial firms. These firms are attracting huge amounts of private investment, and commentators have argued that they are attracting the most talented and hard-working employees (Barwise \& Watkins 2018, Bloom 2017). They are now achieving levels of dominance in their chosen business areas that policymakers and the general public find unacceptable, and yet for the most part they are not breaking any laws.

Second, we are seeing attempts by traditional firms, with their roots in the industrial era, seeking to respond in a variety of ways. In terms of size and scope, many of them are experimenting with platform-like business models of their own, though not always successfully. In terms of structure and organisation, they are seeking to become leaner and more agile, using the new ways of working of digital firms, but again with mixed levels of success. There have been quite a lot of cases of traditional firms going out of business because of their failure to adapt. In many other cases, there is sufficient inertia in the behaviour of consumers that traditional firms are continuing to survive. Banking, for example, is a hotbed of technological innovation, and yet most established retail banks are still retaining their positions of strength.

Third, institutional structures are evolving in response to the digital revolution, but typically very slowly. We examined four specific sets of institutions, and we observed that intellectual property ownership rules have adapted successfully to the 
economics of digital production, through such innovations as the General Public Licence. The other three (employment law, audit and measurement, and competition policy) are moving more slowly, with many observers recognising the need for changes to be made, but little agreement about what those changes should be or how they should be enacted. While the way forward in employment law seems relatively straightforward, in terms of new categories of workers, both competition law and the audit and measurement of firm activities are a long way from agreeing how they need to evolve.

The underlying problem, looking across most of these institutions, is the difficulty of valuing information - and particularly information about customers. The reason these digital firms are so powerful is that they now have control over huge bodies of data about us as individuals - in terms of what we search for online, what we talk about through our social networks, and how we shop. While policies are being put in place to allow individuals to regain control over this information (for example, the EU General Data Protection Regulation), the bigger opportunity is to find a means of pricing this data in a way that is transparent and acceptable to those individuals. If this were to happen, the prospects of valuing firms more accurately, and curbing their dominant behaviour, would be greater.

Fourth, and building on the above, there is a need for more institutional innovation: that is, the development of innovative policies and regulations to support the new ways of working that firms have put in place to compete in the digital era. One example noted in this paper is Richard Stallman's invention of the General Public License for software, but such instances are still very rare. It would be very useful for additional research to be carried out in this area: for example, identifying other instances of institutional innovations that support digital-era business models and ways of working, and the roles played by different actors (governments, activists, firms) in implementing them.

As a final point, one of the themes cutting across this entire review is the trend towards computer-based automation, and the possibility that smaller number of jobs will be available in the future. This is a hotly debated issue (e.g., Mortensen \& Pissarides 1998). Techno-optimists argue that, whenever a new technology comes along, some categories of jobs are destroyed, and other categories of entirely new jobs are created in their place. Techno-pessimists counter that the fourth industrial revolution is different from the three previous ones because of the breadth of traditional work it is supplanting, and therefore that it will result in wide-scale unemployment. This paper does not take a strong position vis-à-vis the debate on the future of jobs, but its conclusions are closer to the pessimistic end of the spectrum: that is, that there will be fewer jobs available in the years ahead. 
To the extent that jobs are disappearing, what should businesspeople do? It is very hard for individual firms to take responsibility here, because in a competitive market there is an incentive to match the cost structure of one's competitors, which often means employing fewer people. Nonetheless, there is one area where firms could be more creative, and that is in employing more people but for fewer hours each, thereby keeping the overall costs of employment at similar levels. Job-sharing arrangements have been trialled over the years, without much success, but to the extent that people are increasingly choosing freelance arrangements, there is more scope for flexible work than before. Again, this is an issue that warrants further research attention, to see whether it provides an opportunity for progress.

\section{REFERENCES}

Arthur, W. Brian (1994), Increasing Returns and Path Dependence in the Economy (Ann Arbor, MI, University of Michigan Press). https://doi.org/10.3998/mpub.10029

Balaram, Brhmie, Warden, Josie \& Wallace-Stephens, Fabian (2017), 'Good Gigs: A Fairer Future for the UK's Gig Economy', RSA.

https://www.thersa.org/discover/publications-and-articles/reports/good-gigs-a-fairer-future-for-the-uksgig-economy

Baldwin, Carliss Young \& Clark, Kim B. (2000), Design Rules: The Power of Modularity Volume 1. (Cambridge, MA, MIT Press).

Barley, Stephen R. \& Kunda, Gideon (1992), 'Design and Devotion: Surges of Rational and Normative Ideologies of Control in Managerial Discourse', Administrative Science Quarterly, 37: 363-99. https://doi.org/10.2307/2393449

Barwise, Patrick \& Watkins, Leo (2018), 'The Evolution of Digital Dominance: How and Why We Go to GAFA', in Martin Moore \& Damian Tambini (eds) Digital Dominance: Risks and Implications (Oxford, Oxford University Press), 21-49.

Birkinshaw, Julian (2010), Reinventing Management: Smarter Choices for Getting Work Done (Chichester, John Wiley).

Birkinshaw, Julian \& Ridderstråle, Jonas (2017), Fast/Forward: Make your Company Fit for the Future (Stanford, CA, Stanford University Press).

Bloom, Nicholas (2017), 'Corporations in the Age of Inequality', Harvard Business Review. https://hbr. org/cover-story/2017/03/corporations-in-the-age-of-inequality

Bodrožić, Zlatko \& Adler, Paul S. (2018), 'The Evolution of Management Models: A Neo-Schumpeterian Theory', Administrative Science Quarterly, 63: 85-129. https://doi.org/10.1177/0001839217704811

Bryant, C. (2018), 'Spotify's \$26 Billion Value Is Hard to Put Your Finger On', Bloomberg Business Week. Brynjolfsson, Erik \& McAfee, Andrew (2014), The Second Machine Age: Work, Progress, and Prosperity in a Time of Brilliant Technologies (New York, W. W. Norton).

Carr, Nicholas G (2008), The Big Switch: Rewiring the World, from Edison to Google (New York, W. W. Norton).

Castells, Manuel (1996), The Rise of the Network Society. The Information Age: Economy, Society, and Culture (Oxford, Blackwell).

Chandler, Alfred D. (1990), Scale and Scope: The Dynamics of Industrial Competition (Cambridge, MA, Harvard Business School). 
Christidis, Konstantinos \& Devetsikiotis, Michael (2016), 'Blockchains and Smart Contracts for the Internet of Things', IEEE Access, 4: 2292-303. https://doi.org/10.1109/ACCESS.2016.2566339

Coase, Ronald (1937), 'The Nature of the Firm', Economica, 4(16): 386-405. http://doi:10.1111/j.1468-0335.1937.tb00002.x

Davenport, Thomas H. (1993), Process Innovation: Reengineering Work through Information Technology (Cambridg, MA, Harvard Business Press).

Davenport, Thomas H. \& Ronanki, Rajeev (2018), 'Artificial Intelligence for the Real World', Harvard Business Review, 96(1): 108-16.

DCMS (2018), Disinformation and 'Fake News': Interim Report, Digital, Culture, Media and Sport Committee, House of Commons. https://publications.parliament.uk/pa/cm201719/cmselect/cmcumeds/363/363.pdf

Denning, Stephen (2018), The Age of Agile: How Smart Companies are Transforming the Way Work Gets Done (New York, AMACOM).

Edvinsson, Leif \& Malone, Michael (1997), Intellectual Capital. (New York, Harper Collins).

Evans, David S. \& Schmalensee, Richard (2016), Matchmakers: The New Economics of Multisided Platforms (Cambridge, MA, Harvard Business Review Press).

Granovetter, Mark (1992), 'Economic Institutions as Social Constructions: A Framework for Analysis', Acta Sociologica, 35(1): 3-11. https://doi.org/10.1177/000169939203500101

Grant, Robert M. (1996), 'Toward a Knowledge-based Theory of the Firm', Strategic Management Journal, 17(S2): 109-22. https://doi.org/10.1002/smj.4250171110

Handy, Charles (1989), The Age of Unreason (Boston, MA, Harvard Business School Press).

Haskel, Jonathan \& Westlake, Stian (2017), Capitalism Without Capital: The Rise of the Intangible Economy (Princeton, NJ, Princeton University Press).

Hill, Andrew (2016), 'When McKinsey Met Uber: The Gig Economy Comes to Consulting', Financial Times, 6 October. https://www.ft.com/content/a5419fca-7f24-11e6-bc52-0c7211ef3198

Hippel, Eric von \& von Krogh, Georg (2003), 'Open Source Software and the "Private-collective" Innovation Model: Issues for Organization Science', Organization Science, 14: 209-23. https://doi.org/10.1287/orsc.14.2.209.14992

Hollingsworth, J. Rogers \& Boyer, Robert (eds) (1997), Contemporary Capitalism: The Embeddedness of Iinstitutions (Cambridge, Cambridge University Press). https://doi.org/10.1017/CBO9781139174701

Horn, Jeff (2007), The Industrial Revolution: Milestones in Business History (London, Greenwood Press). Innosight (2018), 'Corporate Longevity Forecast', research report. www.innosight.com

Jacques, Roy (1996), Manufacturing the Employee: Management Knowledge from the 19th to 21 st Centuries (Thousand Oaks, CA, SAGE).

Jensen, Michael C. \& Meckling, William H. (1976), 'Theory of the Firm: Managerial Behavior, Agency Costs and Ownership Structure', Journal of Financial Economics, 3: 305-60.

https://doi.org/10.1016/0304-405X(76)90026-X

Kay, John (2011), Obliquity: Why Our Goals Are Best Achieved Indirectly (London, Profile Books).

Khan, Lina M (2016), 'Amazon's Antitrust Paradox', Yale Law Journal, 126: 710.

Kogut, Bruce \& Zander, Udo (1996), 'What Firms Do? Coordination, Identity, and Learning', Organization Science, 7: 502-18. https://doi.org/10.1287/orsc.7.5.502

Lev, Baruch (2000), Intangibles: Management, Measurement, and Reporting (Washington, DC, Brookings Institution Press).

Leavitt, H. J. \& Whisler, T. L. (2000), 'Management in the 1980s', in I. McLoughlin, D. Preece \& P. Dawson (eds) Technology, Organizations and Innovation: The Early Debates (London, Taylor and Francis).

Lynch, David (2017), 'Big Tech and Amazon: Too Powerful to Break Up?', Financial Times, 30 October. https://www.ft.com/content/e5bf87b4-b3e5-11e7-aa26-bb002965bce8 
Martin, Carolyn A. \& Tulgan, Bruce (2013), Managing Generation Y (Amherst, MA, HRD Press).

McGregor, Douglas (1996), The Human Side of Enterprise (New York, McGraw-Hill); first published 1960.

McIntyre, David P. \& Srinivasan, Arati (2017), 'Networks, Platforms, and Strategy: Emerging Views and Next Steps', Strategic Management Journal, 38(1): 141-60. https://doi.org/10.1002/smj.2596

Micklethwait, John \& Wooldridge, Adrian (2005), The Company: A Short History of a Revolutionary Idea (New York, Random House).

Moran, Peter \& Ghoshal, Sumantra (1999), 'Markets, Firms, and the Process of Economic Development', Academy of Management Review, 24: 390-412. https://doi.org/10.5465/amr.1999.2202128

Mortensen, Dale T. \& Pissarides, Christopher A. (1998), 'Technological Progress, Job Creation, and Job Destruction', Review of Economic Dynamics, 1: 733-53. https://doi.org/10.1006/redy.1998.0030

Negroponte, Nicholas (1995), Being Digital (New York, Alfred A. Knopf).

Parker, Geoffrey G., Van Alstyne, Marshall W. \& Choudary, Sangeet Paul (2016), Platform Revolution: How Networked Markets Are Transforming the Economyand How to Make Them Work for You (New York, W. W. Norton).

Pink, Daniel H. (2011), Drive: The Surprising Truth About What Motivates Us (London, Penguin).

Prahalad, C. K. \& Hamel, G. (1990), 'The Core Competence of the Corporation', Harvard Business Review, 68(3): 79-91.

Prassl, J. (2017), Humans as a Service: The Promise and Perils of Work in the Gig Economy (Oxford, Oxford University Press).

Quinn, James Brian (1992), Intelligent Enterprise: A Knowledge and Service Based Paradigm for Industry (New York, Simon and Schuster).

Rochet, Jean-Charles \& Tirole, Jean (2003), 'Platform Competition in Two-sided Markets', Journal of the European Economic Association, 1: 990-1029. https://doi.org/10.1162/154247603322493212

Schumpeter, Joseph A. (1934), The Theory of Economic Development (Cambridge, MA, Harvard University Press).

Schwab, Klaus (2017), The Fourth Industrial Revolution (New York, Crown Business).

Shapiro, Carl \& Varian, Hal R. (1998), Information Rules: A Strategic Guide to the Network Economy (Cambridge, MA, Harvard Business Press).

Soskice, David W. \& Hall, Peter A. (2001), Varieties of Capitalism: The Institutional Foundations of Comparative Advantage (Oxford, Oxford University Press).

Williams, S. (2002), Free as in Freedom: Richard Stallman's Crusade for Free Software (Sebastopol, CA, O'Reilly Media).

Williamson, Oliver (1975), Markets and Hierarchies (New York, Macmillan).

Williamson, Oliver (1985), The Economic Institutions of Capitalism (New York, Free Press).

Wren, Daniel A. (1998), Management Innovators: The People and Ideas That Have Shaped Modern Business (Oxford, Oxford University Press).

Yoo, Youngjin, Henfridsson, Ola \& Lyytinen, Kalle (2010), 'Research Commentary-The New Organizing Logic of Digital Innovation: An Agenda for Information Systems Research', Information Systems Research, 21: 724-35. https://doi.org/10.1287/isre.1100.0322

Note on the author

Julian Birkinshaw is Professor of Strategy and Entrepreneurship, London Business School and is a Fellow of the British Academy.

jbirkinshaw@london.edu 
To cite the article: Julian Birkinshaw (2018), 'How is technological change affecting the nature of the corporation?', Journal of the British Academy, 6(s1): 185-214. DOI https://doi.org/10.5871/jba/006s1.185

This article is licensed under a

Creative Commons Attribution-NonCommercial-NoDerivs 4.0 Unported License.

Journal of the British Academy (ISSN 2052-7217) is published by

The British Academy - the national academy for the humanities and social sciences.

10-11 Carlton House Terrace, London, SW1Y 5AH

www.britac.ac.uk 